\title{
Physico-sensory and Textural Properties of Composite Millet Palm Jaggery Muffins
}

\author{
Snehal Jadhav ${ }^{1}$, V. Kavinya ${ }^{2}$, R. Vijay Nirmal ${ }^{2}$, H. Mohammed Shameem ${ }^{2}$ and K. Ramalakshmi ${ }^{\text {* }}$ \\ ${ }^{1}$ Rajalakshmi Engineering College, Thandalam - 602 105, Tamil Nadu, India; ramal_kumar@yahoo.com \\ ²Bannari Amman Institute of Technology, Sathyamangalam - 638 401, Tamil Nadu, India
}

\begin{abstract}
Composite millet palm jaggery (CMPJ) muffins were prepared by replacing all-purpose flour with composite millet flour at different level $(0: 100,50: 50,30: 70)$ and replacing cane sugar completely with palm jaggery. CMPJ muffins and control muffins with cane sugar (APFS) were analyzed for Physico-sensory and textural properties (TPA). Incorporation of millet flour and wheat flour at the ratio 70:30 resulted in an acceptable product with good sponginess which is one of the desirable properties of muffins. The moisture content of muffins prepared with palm jaggery was found to be higher $(21.84 \pm 0.01 \%)$ than muffins prepared with sugar $(19.58 \pm 0.01 \%)$. The lightness of the crumb and crust $(37.58 \pm 0.08,28.89 \pm 0.11)$ of CMPJ muffins were found to be lesser than control muffins (58.34 $\pm 0.20,35.30 \pm 0.99)$, whereas redness of crumb and crust was found more in CMPJ muffins $(9.18 \pm 0.07,12.12 \pm 0.22)$ than APFS muffins $(6.56 \pm 0.15,10.61 \pm 0.15)$ which is due to the brown colour of palm jaggery. The muffins with jaggery had lower $\mathrm{pH}$ and sensory score and higher water activity (aw) than muffins with sugar. TPA results showed that CMPJ ( $6270 \pm 7.2 \mathrm{~g}$ ) were slightly harder than APFS (4729 \pm 4.7$)$. Microbial analysis (Total plate count, Yeast and mold count) for CMPJ muffins was found to be safe for consumption upto 12 days without added preservative. It is concluded that CMPJ muffins (without preservative) can be an alternative to APFS without affecting the quality parameters of the product.
\end{abstract}

Keywords: All Purpose Flour, All Purpose Flour Sugar Muffins (APFS), Cane Sugar, Composite Millet Flour, Composite Millet Palm Jaggery Muffins (CMPJ), Palm Jaggery

\section{Introduction}

Millets is one of the $6^{\text {th }}$ cereal crops in terms of world agriculture production, grown under drought condition compare to major cereals. It has resistance to pest and diseases, short growing season and productivity ${ }^{1}$. Millets serve as a major food component and various traditional food and beverages such as bread, porridges and snack foods are made up of millets. Millets are small-seeded with different varieties such as pearl millet (Pennisetumglaucum L.), finger millet (Eleusinecoracana L.), kodo millet (Paspalumsetaceum L.), proso millet (Penicummiliaceum L.), foxtail millet (Setariaitalic L.) and little millet (Panicumsumatrense L.). In addition to nutritive value, millets are having several health benefits viz., preventing cancer and cardiovascular diseases, reducing tumor incidence, lowering blood pressure, reducing risk of heart diseases, cholesterol, rate of fate absorption and also in delaying in gastric emptying. Therefore, millet grains are now receiving specific attention from these developing countries in terms of utilization as food as well as from some developed countries in terms of its good potential in the manufacturing of bioethanol and biofilms ${ }^{2}$.

Palm jaggery is traditional, non-centrifugal palm sugar consumed in Asia, Africa and in some countries in the America. It is a concentrated product of palm sap without separation of the molasses and crystals can vary from golden brown to dark brown in colour. It has an intense, reminisced chocolate taste. The colour of palm jaggery after processing turns dark brown and is highly priced due to its medicinal properties. Palm jaggery is most popular in southern India states viz Tamil Nadu

*Author for correspondence

Article Received on: 24.06 .2020

Revised on: 20.12 .2020

Accepted on: 27.01.2021 
(Karupatti, vellamorpanavellam), Karnataka (thaatibella), Kerala and Andhra Pradesh ${ }^{3}$. Palm jaggery contains $90.60 \%$ carbohydrate and also it is one of the richest source of iron $(2.5 \mathrm{mg} / \mathrm{gm})$, thiamin $(24 \mathrm{mg} / 100 \mathrm{gm})$ and riboflavin (432mg/100gm).

Bakery products with incorporation of nutritional component are an important part of balancing our diet since thousands of years. The aim of this study is to develop the millet based muffins with palm jaggery as a natural sweetener without addition of preservative.

\section{Materials and Methods}

\subsection{Materials}

Commercial all-purpose flour, composite millet flour (kodo, proso, foxtail, little, barnyard, finger millets), palm jaggery, cane sugar, butter and milk were purchased from local market. Vanillaessesnce (BushBoake Allen Ltd., Chennai, India), plate count agar, E. coli agar, potato dextrose agar media were purchased from HiMedia Mumbai, India. All the other chemicals were procured from Merck, Mumbai.

\subsection{Muffins Formulation and Processing Conditions}

Muffins with the ingredients (Table 1) were prepared according to the method ${ }^{4,5}$. All-purpose flour, composite millet flour, baking powder, salt and powdered sugar were sieved separately thrice for uniform mixing. Palm jaggery was used in the form of a solution by diluting with water in the ratio of 1: 1 . Butter and powdered sugar/palm jaggery were mixed using Sinmag planetary mixer (model no:
SM- 5L) for $3 \mathrm{~min}$ at $120 \mathrm{rpm}$ to get a uniform mixture. Simultaneously, egg white, egg yolk and essence were whipped at $170 \mathrm{rpm}$ for $5 \mathrm{~min}$. The whipped egg mixture was mixed with cream in four parts to avoid curdling of cream. It was then mixed with all-purpose flour and composite millet flour at $120 \mathrm{rpm}$ for $1 \mathrm{~min}$ to get a homogeneous mix. Cake batter was transferred into cake pan, baked at $180^{\circ} \mathrm{C}$ for $25 \mathrm{~min}$ in a OTG oven (Sinmag). The muffins were prepared with various formulations denoted as A, B, C, D, E and F respectively. After baking, the muffins were allowed to cool at room temperature and packed with air polythene pouches and stored at an ambient temperature. The muffins were subjected to physico-chemical, textural and sensory analysis during storage.

\subsection{Storage of Muffins}

CMPJ muffins and APFS muffins (control sample) were packed in polythene pouches and shelf life studies were conducted. Muffins were stored at room temperature $\left(30 \pm 2^{0} \mathrm{C}\right)$ for 16 days. The samples were analyzed for colour, water activity, $\mathrm{pH}$, texture, titratable acidity, microbial analysis, sensory evaluation at an interval of 4 days upto the storage period.

\section{Methods}

Muffins were analysed for physico- chemical parameters for muffins such as $\mathrm{pH}$, colour, volume according to the standard procedures ${ }^{6}$. Colour (crust and crumb) of the muffins were evaluated using Hunter Lab Colour measuring system (Labscan XE system, Reston, USA) and water activity of the product was analyzed using AquaLab

Table 1. Formulations prepare at different level with composite millet flour, all purpose flour and palm jaggery

\begin{tabular}{|c|c|c|c|c|c|c|}
\hline \multirow{2}{*}{ Ingredient (g) } & \multicolumn{6}{|c|}{ Composition of all purpose flour with CMF and palm jaggery } \\
\hline & A & B & C & D & $\mathbf{E}$ & $\mathbf{F}$ \\
\hline All purpose flour & 100 & 100 & 100 & - & 50 & 30 \\
\hline Composite millet flour & - & - & - & 100 & 50 & 70 \\
\hline sugar & 100 & - & - & - & - & - \\
\hline palm jaggery & & 100 & 150 & 150 & 150 & 150 \\
\hline Butter & 65 & 65 & 65 & 65 & 65 & 65 \\
\hline Egg white & 62 & 62 & 62 & 62 & 62 & 62 \\
\hline Egg yolk & 30 & 30 & 30 & 30 & 30 & 30 \\
\hline Baking powder & 1.7 & 1.7 & 1.7 & 1.7 & 1.7 & 1.7 \\
\hline Vanilla essence $(\mathrm{ml})$ & 1.5 & 1.5 & 1.5 & 1.5 & 1.5 & 1.5 \\
\hline Milk (ml) & 25 & 25 & 25 & 25 & 25 & 25 \\
\hline
\end{tabular}

Bold values are variations of palm jaggery, composite millet flour and all-purpose flour 
Pre water activity meter. The $\mathrm{pH}$ of muffin samples was measured by using a $\mathrm{pH}$ meter (Eutech Instruments $\mathrm{pH}$ 510, Ayer Rajah Crescent, Singapore) by dissolving $10 \mathrm{~g}$ of sample with $10 \mathrm{ml}$ of distilled water and readings were noted.

\subsection{Volume of Muffins}

Volume of muffins was determined by using rapeseed displacement. An empty pan was filled with rapeseed and the volume of the pan was observed on the basis of rapeseed volume by graduated cylinder $\left(A_{1}\right)$. Thereafter muffins were placed in the pan. The rest of the volume was filled by rapeseed and the volume of rapeseed was calculated by graduated cylinder $\left(B_{2}\right)$. Muffin volume was determining by $A_{1}-B_{2}$.

\subsection{Colour of Muffins}

The colour analysis of crust and crumb of the muffins were done using Hunter Lab Colour measuring system (Labscan XE system, Reston, USA). The colour measurement of muffins sample were performed through $6.4 \mathrm{~mm}$ diameter of diaphragm containing an optical glass which is placed on the sample holder and reflectance was auto-recorded for the wavelength ranging from 360-800 $\mathrm{nm}$. The parameter determined were $\mathrm{L}, \mathrm{a}, \mathrm{b}^{8}$. Each value represents the means of triplicate readings.

\subsection{Texture Profile Analysis}

The texture analysis of CMPJ muffin and cane sugar muffin was carried out by using Texture profile analyser(TPA), (Model TA-XT. plus, Stable Micro Systems, Godalming, UK). Measurement was conducted using a $50 \mathrm{~kg}$ load cell and cylindrical aluminum probe $36 \mathrm{~mm}$ diameter. Maximum force required for $25 \%$ compression of the muffins were recorded. The results recorded were as an average of three replicates. The texture determination was carried out after removing the crust from the muffin surface. Hardness of the muffins was analyzed.

\subsection{Sensory Evaluation of Muffins}

Sensory evaluation of muffins was carried out using 9 Point Hedonic scaleby 14 trained panelist (Professors and students, Department of Food Technology, BIT, Tamil $\mathrm{Nadu}$ ) at 4 days' interval after production. Each panelist was provided with the muffins sample with a randomized code. Sensory evaluation was done at room temperature in between the hours of 10.00 to 11.00 am and the test was conducted under day light illumination. Normal water and mouth refreshing sample (puffed rice) were served in between samples to eliminate the residual test of the previous sample.

\subsection{Microbial Analysis of Muffins}

Microbial analysis of muffins was done during storage study at 4 days' interval. Total plate count (TPC), Yeast and mold count (Y\&M) was done using nutrient agar and potato dextrose agar respectively ${ }^{9}$. The microbial analysis of muffins was carried out using serial dilution agar plate technique, $1 \mathrm{~g}$ of muffin sample was suspended and agitated in $9 \mathrm{ml}$ of water blank (to make volume upto $10 \mathrm{ml}$ ) to form microbial suspension. Subsequently, samples were diluted decimally and $0.1 \mathrm{ml}$ aliquots were inoculated on TPC and Y\&M respectively.

\subsection{Statistical Analysis}

Statistical analysis of all the experiments was carried out in triplicates and analyzed statistically with different experimental group using Duncan's news multiple range test (DMRT) statistica software version 7.0 of Stat Soft Incorporation, Tulsa, OK, USA as per the method ${ }^{10}$. The significance level was established at $\mathrm{p}<0.05$.

\section{Results and Discussion}

\subsection{Optimization of Formulations for Muffins}

The composite millet flour used for the study had $10.36 \%$ moisture, $11.16 \%$ protein, $1.12 \%$ fat, $0.86 \%$ ash and $0.41 \%$ total sugars. The sugar and jaggery powder was found to possess $0.82 \%$ and $6.88 \%$ moisture, ash (0.18 and $0.74 \%)$ and total sugar (96 and 70.13\%). These results showed jaggery is rich in minerals. The moisture and total sugar content of jaggery are within the specified limit ${ }^{11}$.

The quality characteristics of muffins with sugar and palm jaggery are furnished in Table 2 . There is not much variation in weight of muffins $(30-35 \mathrm{~g}$ ) with different percentage of composite millet flour, all-purpose flour and palm jaggery which reveals the processing and baking conditions are uniform throughout the experiments. Volume of sample B and C is less compared to sample A which may be due to the replacement of palm jaggery which hinders the raising of the muffins during baking. The volume of muffins, not only depends on the incorporation of air inside the batter but also depends on the capacity of the batter to retain air during baking ${ }^{12}$. Effect of formulated composite millet flour and allpurpose flour with palm jaggery has been evaluated for sensory evaluation (using 9-point hedonic scale). During the sensory analysis, colour of crumb and crust of muffins, 
texture, sweetness and overall acceptability parameters were evaluated. From Table. 2, it is observed that Sample A, ie., control muffins prepared using all-purpose flour with cane sugar was preferred by maximum number of panelists. Sample B and C of CMPJ muffins formulated with $100 \mathrm{~g}$ and $150 \mathrm{~g}$ of palm jaggery were evaluated for the equivalent sweetness level of CMPJ muffins with APFS muffins. Sample C (150g) was preferred by the panelists who provided equivalent sweetness to cane sugar muffins. Samples, D, E, F contain ratio of composite millet flour: all-purpose flour in proportion to 100:00, 50:50, 70:30 respectively. The sample $\mathrm{D}$ tasted floury during eating and also the sample was more hard. Sample E and F provided equivalent OQS which equal to Sample A. Sample F, with the ratio of composite millet flour: all-purpose flourat 70:30, was optimized due to its nutritional importance. On the basis of composite millet flour's nutritional value, we optimized sample F, ratio of its composite millet flour: all-purpose flour (70:30) for further storage study.

Texture profile analysis was carried out for all the formulated muffins. It is observed that the softness of APFS muffins is highest compared to CMPJ muffins. The hardness of all the formulations significantly differ from each other, which is a clear indication that hardness of the muffins depends on the composition as well as the ingredients used for making muffins. The hardness of Sample A is $4729 \mathrm{~g}$ which is the control sample. Hardness of sample B and C is $4699 \mathrm{~g}$ and $2436 \mathrm{~g}$ respectively. From sample B and C, we conclude that Sample C is softer than sample $B$ because of the concentration of palm jaggery. Sample D is having a hardness of $8174 \mathrm{~g}$ because of its $100 \%$ composite flour which doesn't have elasticity which may be due to the absence of gluten which is one of the important ingredient for the bakery products. Replacement of 50\% all-purpose flour with $50 \%$ composite millet flour reduces the hardness to $6274 \mathrm{~g}$. Further replacement of $70 \%$ allpurpose flour, though the muffins possess the hardness of $6295 \mathrm{~g}$, there is no significant difference in OQS between Samples E and F. Hence, the formulation with the replacement of $70 \%$ all-purpose flour with composite millet flour was chosen for further shelf life studies.

\subsection{Quality Characteristics of Muffins}

Physico-chemical and sensory evaluation of muffins were carried out for both APFS muffins and CMPJ muffins during the storage period. The moisture content of APFS muffins was lesser (19.58\%) compared to palm jaggery muffins sample (21.84\%) which is due to the presence of higher invert sugar and hygroscopic nature of palm jaggery ${ }^{13}$. As expected, ash content is more in palm jaggery muffins (1.32\%) compared to sugar based muffins

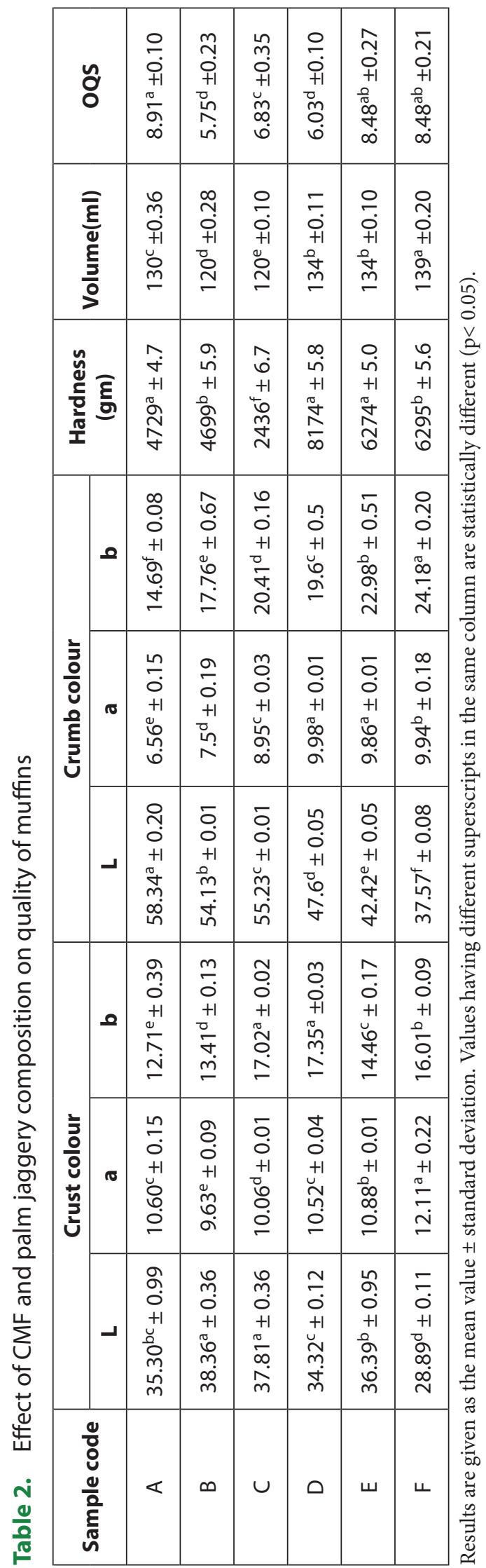


$(0.85 \%)$. The protein and fat content of palm jaggery muffins are slightly lesser (6.89\% and 30.24\%) than muffins with sugar $(6.98 \%$ and $34.56 \%)$. The sugar content in CMPJ muffins was found to be $26.41 \%$, which is lower than the APFS muffins (33.21\%). Jaggery is a good source of iron, calcium, phosphorous and contains less amount of sucrose than cane sugar which is the cause of higher ash content and lesser sugar content of CMPJ muffins than APFS muffins ${ }^{14}$.

\subsection{Effect of Storage on the Quality of Muffins}

Effect of storage on various quality parameter during the storage study was evaluated for CMPJ muffins for 16 days and compared with sugar muffins and the results are presented in Table 3.

The water activity of CMPJ and cane sugar muffins was increased from 0.70 to 0.88 and 0.71 to 0.80 respectively (Figure 1). CMPJ muffins have higher water activity (aw) compared to cane sugar muffins. Similar result was observed for water activity of muffins prepared using various fiber and natural sweetener Stevia by replacement of cane sugar ${ }^{15}$. The $\mathrm{pH}$ activity of CMPJ muffins and cane sugar muffins was observed to decrease slightly during storage from 7.81 to 7.6 and 7.12 to 7.10 respectively. Decrease in water activity and $\mathrm{pH}$ of muffins were found to be similar as reported ${ }^{16}$. Titratable acidity of palm jaggery muffins during storage was observed to increase after 4 days, while it reduced in case of APFS muffins at the end of storage period.

From Table 3, it is observed that the CMPJ muffins showed higher moisture content when compared to cane sugar muffins initially as well as during storage period of 16 days. The moisture content decreased extensively in muffins from 0 to 16 days of storage period. It is observed that the moisture content of CMPJ and APFS muffins sample reduced upto $8^{\text {th }}$ day and slightly increased on $12^{\text {th }}$ and $16^{\text {th }}$ days. Reduction in moisture can be attributed to retrogradiation and staling. CMPJ muffins and cane sugar based muffins showed similar reduction in moisture during storage upto $8^{\text {th }}$ day.

Colour analysis of crust and crumb of CMPJ and APFS muffins was done during storage study. The change in colour (Lab value) values of crust and crumb of both muffin samples was very less different during 16 days of storage period. TPA of muffins was analysed during storage for hardness compared to that of sugar muffin sample. Initially, the hardness of CMPJ muffins was found to be more than the control muffin sample, $6270 \mathrm{~g}$ and $4729 \mathrm{~g}$ respectively. The hardness of CMPJ and APFS muffins were increased during storage upto 8 days $13947 \mathrm{~g}$

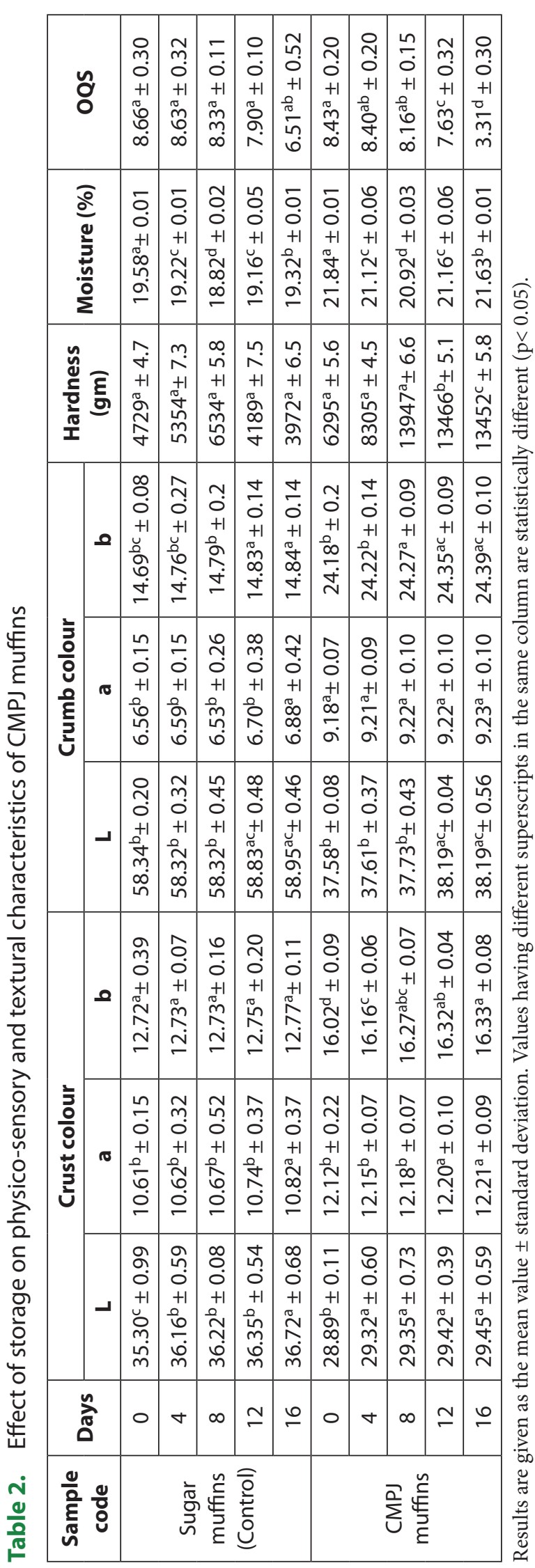


and $6534 \mathrm{~g}$ and reduced on $12^{\text {th }}$ and $16^{\text {th }}$ day upto $13452 \mathrm{~g}$ and $3972 \mathrm{~g}$ owing to oxidation as well as microbial growth which softens the muffins. The overall acceptability of both the muffin samples was evaluated and found that the overall acceptability of muffin samples was good upto 8 days.
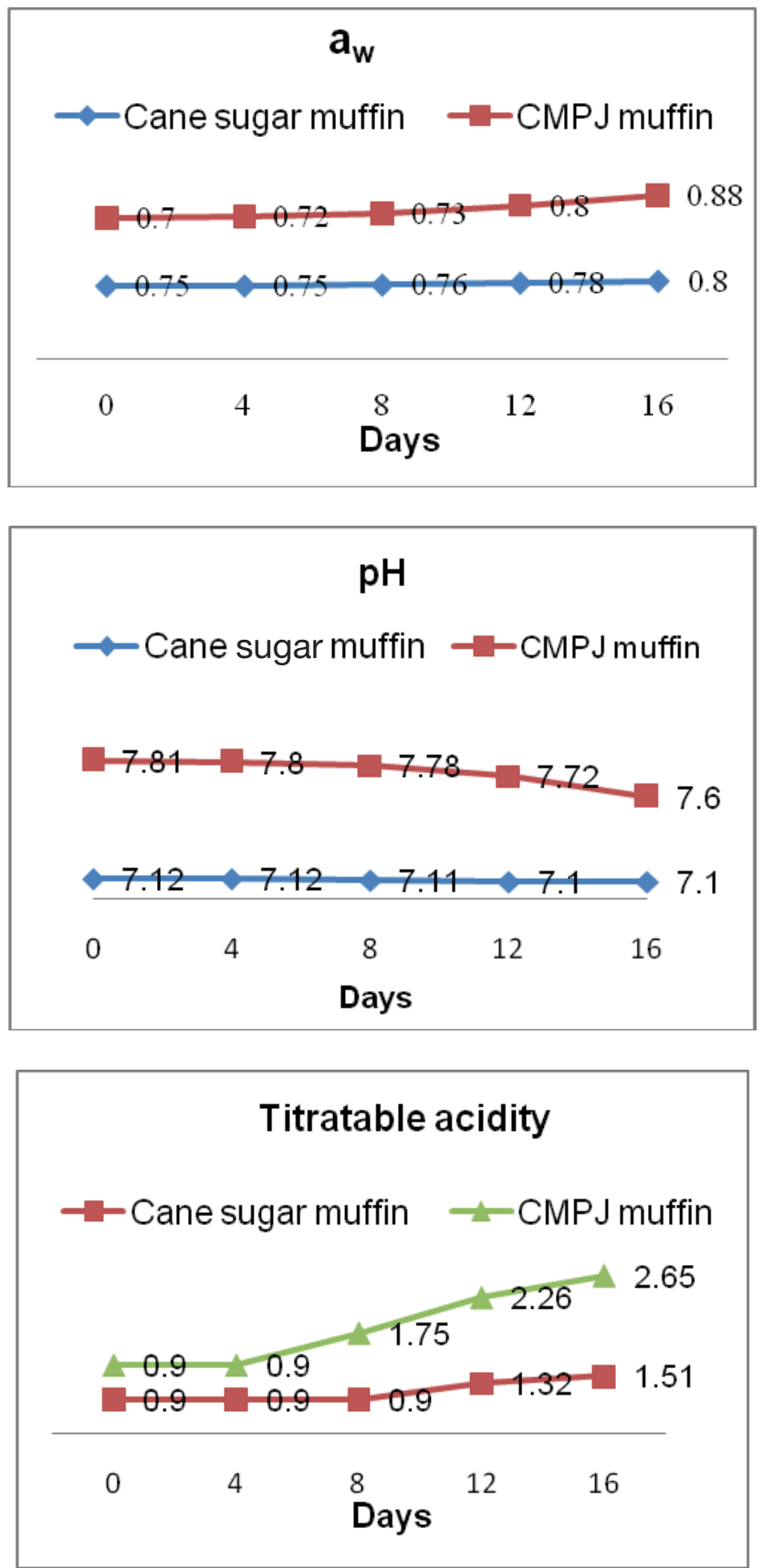

Figure 1. Effect of storage period on water activity (aw), $\mathrm{pH}$ and Titrable acidity of CMPJ and cane sugar muffins.

\subsection{Microbial Quality of Muffins During Storage}

The microbial analysis of muffins was performed during storage studies at room temperature $30 \pm 2^{\circ} \mathrm{C}$ for 16 days. The microbial analysis of muffin samples was performed for TPC and Y\&M. During the storage study, E.coli and Salmonella were not detected in both the muffin samples. The count as well as the proliferation of TPC and Y \&M was more in CMPJ muffins compared to APFS muffins. The TPC count was in the range of 2.3 to $3.87(\log \mathrm{CFU} / \mathrm{g})$ and $\mathrm{Y} \& \mathrm{M}$ was in the range of 2.15 to $2.89 \log \mathrm{CFU} / \mathrm{g}$ with increase in storage period from 0 to 8 days.

Total aerobic microbial count was lower than 4 log $\mathrm{CFU} / \mathrm{g}$ as specified for bakery product by UK Sodexo Standards and Yeast \& Mold was lower than $3 \log \mathrm{CFU} / \mathrm{g}$ as recommended by Woolworth quality assurance standards Guidelines ${ }^{17}$. With the recommended limits, CMPJ muffins sample is safe for consumption upto 8 days because on $12^{\text {th }}$ and $16^{\text {th }}$ days, the $Y \&$ M growth of CMPJ muffins (3.87 log CFU/g) and TPC (4.32 log CFU/g) exceeded the recommended limit and hence the shelf-life is concluded as 8 days.

\section{Conclusion}

Composite millet flour based muffins with palm jaggery as a natural sweetener was optimized using different formulation of composite millet flour: all purpose flour (100:0, 50:50, 70:30) and Palm jaggery (100g and 150g). From physico-sensorial properties, it is observed that the composite millet flour: all-purpose flour at the ratio of $70: 30$ with $150 \mathrm{~g}$ palm jaggery provided equivalent sweetness and overall acceptability. The CMPJ muffins showed lower $\mathrm{pH}$ and increase in titratable acidity. CMPJ muffins had higher moisture content, ash, protein and carbohydrate as compared to APFS muffins. CMPJ muffins showed lower value for lightness, higher value for redness and yellowness compared to cane sugar muffins. TPA and OQS was analyzed during the 16 days storage. Microbial analysis of muffin sample was carried out for TPC and Y\&M and it was observed that the product was acceptable for consumption upto 8 days without addition of any preservatives.

\section{References}

1. Devi PB, Vijayabharathi R, Sathyabama S, Malleshi NG, Priyadarisini VB. Health benefits of finger millet (Eleusine coracana L.) polyphenols and dietary fiber: A review. J Food Science and Technol. 2014; 51(6) :1021-40. https://doi.org/10.1007/s13197-011-0584-9. PMid:24876635 PMCid:PMC4033754 
2. Li J, Chen Z, Guan X, Liu J, Zhang M, Xu B. Optimization of germination conditions to enhance hydroxyl radical inhibition by water soluble protein from stress millet. J Cereal Sci. 2008. 48, 619-24. https://doi.org/10.1016/j.jcs.2008.01.008

3. Vengaiah PC, Ravindrababu D, Murthy GN, Prasad KR. Jaggery from Palmyrahpalm (Borassus flabellifer L.) - Present status and scope. Indian Journal of Traditional Knowledge. 2013; 12(4):714-17.

4. Lamdande AG, Khabeer ST, Kulathooran R, Dasappa I. Effect of replacement of sugar with jaggery on pasting properties of wheat flour, physico- sensory and storage characteristic of muffins. 2018, J Food Sci Technol. 2018; 55(8):144-3153. https://doi. org/10.1007/s13197-018-3242-7. PMid:30065425 PM Cid:PMC6046027

5. Jyotsna R, Prabhasankar P, Indrani D, Rao GV. Improvement of rheological and baking properties of cake batters with emulsifier gels. J Food Sci. 2004; 69:16-19. https://doi.org/10.1111/j.1365-2621.2004.t b17880.x

6. Ranganna S. Handbook of analysis and quality control for fruits and vegetable products, 2nd Edn. Tata McGraw Hill Publishing Company Limited, New Delhi; 1986.

7. Elham N, Seyed HP. New concept in reduced-calorie sponge cake production by xylitol and oligofructose. J Food Qual. 2016; 39:627-33. https://doi.org/10.1 $111 /$ jfq. 12233

8. Baixauli R, Salvador A, Fiszman SM. Textural and colour changes during storage and sensory shelf life of muffins containing resistant starch. Eur Food Res Technol. 2008; 226:523-30. https://doi.org/10.10 07/s00217-007-0565-4
9. FSSAI. Manual of methods of analysis of foods microbiological testing. Food Safety and Standards Authority of India, Ministry of health and Family Welfare, Government of India, New Delhi; 2012.

10. Steel RGD, Torrie JH. Principles and procedures of statistics. McGraw-Hill, New York; 1960.

11. FSSAI. Standards for Gur or jaggery, sodium saccharin and calcium saccharin. Food Safety and Standards Authority of India, Ministry of health and Family Welfare, Government of India, New Delhi; 2017.

12. Frye AM, Setster CS. Optimising texture of reduced calorie sponge cakes. Cereal Chem. 1991; 69:338-43.

13. Mandal D, Tudu S, Mitra SR, De GC. Effect of common packing materials on keeping quality of sugarcane jaggery during monsoon season. Sugar Tech. 2006; 8:137-42. https://doi.org/10.1007/BF02943648

14. Rao PVKJ, Das M, Das SK. Jaggery-A traditional Indian sweetener. Indian $\mathrm{J}$ Traditional Knowledge. 2007; 6:95-102.

15. Zahn S, Forker A, Krugel L and Rohm H. Combined use of rebaudioside A and fibers for partial replacement in muffins. LWT Food SciTechnol. 2013; 50:695-701.https://doi.org/10.1016/j.lwt.2012.07.026

16. Jariyawaranugoon U. Combined effect of honey and oxygen absorb packaging on storage quality of chocolate sponge cake. J Food Sci Technol. 2013; 5(3):236-43. https://doi.org/10.19026/ajfst.5.3250

17. Standards WQA. Bakery trade partner [Internet]. 2009. Available from: http://www.wowlink.com.au/ $\mathrm{cmgt} / \mathrm{wcm} / \mathrm{connect} / \mathrm{c} 553 \mathrm{~b} 600433 \mathrm{~d} 39398 \mathrm{a} 129 \mathrm{a}$ a521a80a40/ WQA _Category _ Bakery June09.pdf? MOD5AJPERES 